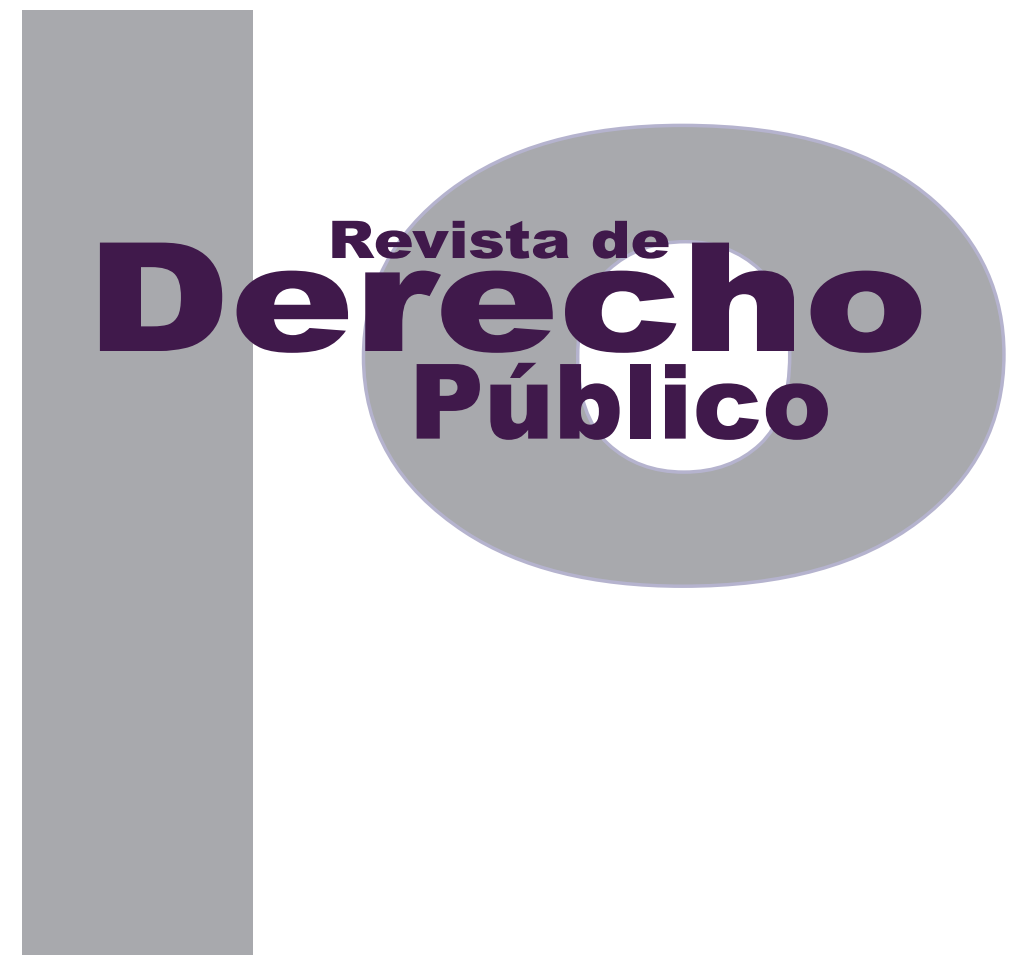

\title{
EL HEGEMÓN, SISTEMA MUNDO ASIMÉTRICO Y EL FLORECIMIENTO DE NUEVAS AMENAZAS EN COLOMBIA
}

\author{
Diana Patricia Arias Henao \\ Artículo de reflexión \\ DOI: http://dx.doi.org/10.15425/redepub.33.2014.26
}

Universidad de los Andes

Facultad de Derecho

Revista de Derecho Público N. ${ }^{\circ} 33$

Julio - Diciembre de 2014. ISSN 1909-7778 


\section{El Hegemón, sistema mundo asimétrico y el florecimiento de nuevas amenazas en Colombia}

\section{Resumen}

El sistema mundo ha variado radicalmente en las interacciones que se suceden en los Estados clásicos y contemporáneos. Igualmente, el tipo de enfrentamientos mutó a nuevas formas, más internas que internacionales, que resultan siendo intermésticas. La política exterior de Colombia está condicionada a la norteamericana, en especial, cuando se refiere a las estrategias para enfrentar las nuevas amenazas de la posguerra. Veamos un ejemplo de ello, en la relación Estados Unidos-Colombia.

Palabras clave: política exterior contemporánea, nuevas amenazas, construcción de poder en el sistema mundo, Estados Unidos, Colombia, narcoviolencia.

\section{The Hegemón, asymmetric world system and the blossoming of new threats in Colombia}

\section{Abstract}

The world system has changed dramatically in terms of the interactions that occur in the classical and contemporary States. Also the type of fighting mutated into new forms, more internal than international, which are being intermestic. Colombia's foreign policy is subject to the U.S., especially when it comes to strategies for dealing with new threats of war. Let's see an example of it, in the relation United Estates - Colombia.

Keywords: contemporary foreign policy, new threats after the war, construction of power in the world system, United States, Colombia, drug violence.

\section{O Hegemon, sistema mundo assimétrico e o florescimento de novas ameaças na Colômbia}

\section{Resumo}

O sistema mundo tem variado radicalmente nas interações que acontecem nos Estados clássicos e contemporâneos.

Igualmente, o tipo de enfrentamentos mudou para novas formas, mais internas do que internacionais, que acabam sendo intermésticas. A política exterior da Colômbia está condicionada à norte-americana, em especial, quando se refere às estratégias de enfrentar as novas ameaças da pós-guerra. Vejamos um exemplo disso, na relação entre Estados Unidos e Colômbia.

Palavras-chave: política exterior contemporânea, novas ameaças, construção de poder no sistema mundo, Estados Unidos, Colômbia, violência narco. 


\title{
El Hegemón, sistema mundo asimétrico y el florecimiento de nuevas amenazas en Colombia*
}

\author{
Diana Patricia Arias Henao**
}

\section{SUMARIO}

Introducción - I. NACIONALISMO DE LA POSGUERRA FRÍA DESPUÉS DEL DERRUMBE DE LA UNIÓN SOVIÉTICA - A. Condicionamientos de la PF a la política exterior colombiana - B. Nuevas guerras: el caso del paramilitarismo en Colombia - C. Factores de reclutamiento paramilitar - D. Factor exógeno como predominante político externo: asimetrías marcadas por la posguerra - II. COOPERACIÓN MILITAR FRENTE A LAS NUEVAS AMENAZAS - III. SUBSIDIARIEDAD DE LA JUSTICIA INTERAMERICANA - A. SIDH: mecanismo de promoción y protección de los DD. HH. - B. Comisión Interamericana de Derechos Humanos (CIDH) - C. Corte Interamericana de Derechos Humanos - 1. Condiciones de facto en Mapiripán (julio 15-20 de 1997) - 2. Mapiripán en el SIDH - 3. Mapiripán después del SIDH - 4. Soberanía y armonización de ordenamientos jurídicos por control de convencionalidad. Beneficios de la política internacional de la posguerra - IV. CONCLUSIONES - Referencias.

Cómo citar este artículo: Arias Henao, D. P. (Diciembre, 2014). El Hegemón, sistema mundo asimétrico y el florecimiento de nuevas amenazas en Colombia. Revista de Derecho Público, 33. Universidad de los Andes (Colombia).

Es producto de la investigación doctoral que sustentó la autora el pasado 28 de noviembre de 2014 en el Instituto de Relaciones Internacionales de la Universidad Nacional de La Plata, Argentina y que fue aprobada con distinciones.

** Abogada, especialista en derecho de las telecomunicaciones, magíster en relaciones internacionales y doctora en relaciones internacionales por la Universidad Nacional de La Plata, Argentina. Actualmente se desempeña como docente de tiempo completo e investigadora de la Facultad de Relaciones Internacionales, Estrategia y Seguridad de la Universidad Militar Nueva Granada y la UNIAGRARIA, y desde agosto de 2014 es editora de la Revista de Relaciones Internacionales, Estrategia y Seguridad de la primera Universidad 


\section{Introducción}

La Unión Soviética y los Estados Unidos (EE. UU.) al resultar vencedores de la Segunda Guerra Mundial (IIGM), se convirtieron en las superpotencias del sistema mundo. La finalización de la ॥Gm fue factor originario del proceso de guerra fría (GF) que impregnó al sistema mundo con la teoría de los bloques de poder, en el marco de un esquema bipolar que tenía establecida la zona de equilibrio, de seguridad y estrategia sobre Europa occidental y Europa oriental.

De esta manera, desde la década del 50, EE. UU. y la Unión Soviética se fortalecieron y empezaron su plan de expansión al Tercer Mundo. Las superpotencias se comunicaron su overkiIling capacity para desaparecer a la otra. EE. UU. "24 veces a la URSs, mientras que esta puede destruir a aquel 42 veces" (Zeraoui, 2011, p. 89).

EE. UU., líder de Occidente, representaba el poderío industrial, nuclear, financiero económico y, por supuesto, militarista. La Unión Soviética concentró su énfasis de poder más en el ámbito político-militar que en su potencial económico (Zeraoui, 2011, p. 82).

Las zonas de equilibrio de cada una de las superpotencias se demarcaron y fueron respetadas recíprocamente. La condición resultante de no invadir las zonas de equilibrio de cada superpotencia es la permanencia en los balances de poder. Es decir, resultaba claro en aquel esquema bipolar que si una u otra superpotencia pasaba de una zona de equilibrio a otra, inme- diatamente se produciría un "cambio cualitativo (sustancial) en el balance de poder" (Silva, 1987 en Zeraoui, 2011, p. 69).

El respetar las zonas de equilibrio consolidó a los territorios periféricos como las zonas de seguridad que representaban barreras de entrada a los reales centros de poder. Aquellas zonas de seguridad blindaron geográficamente a las superpotencias y se consolidaron en dos aristas geoestratégicas: las zonas de influencia y las periferias enlistadas por alianzas políticas.

Las zonas de influencia reflejan los territorios donde no ejercían teóricamente soberanía, una u otra superpotencia, pero donde su condicionamiento exógeno resultaba tan marcado, que en la práctica ejercían el real poder político. Lo anterior era el producto de alianzas políticas condicionadas por los intereses de las superpotencias, que eran otorgados por los líderes periféricos, sin mayores posibilidades de contradicción.

Alianzas políticas periféricas que decantaron el estatocentrismo característico de las relaciones internacionales (RR. II.). Por ende no resultaba necesario que las superpotencias se instalaran dentro de toda el área de sus respectivas zonas de seguridad, sino que establecieran sus condicionamientos sociales, culturales, militares, económicos y, por supuesto, políticos, en las zonas estratégicamente determinadas como de influencia, a través de la consolidación, o mejor, de la imposición de alianzas políticas asimétricas.

En consecuencia con lo descrito, se acoplaron los bloques de poder consolidados, a lo definido 
por George Kennan a través de la doctrina de la contención, y la teoría de los dos mundos de Zhdanov.

Los bloques de poder, representados en un esquema bipolar de poder internacional, se extendieron sobre todo el sistema mundo, mediante amenazas militares durante el proceso que se denominó la guerra fría.

Dicha escena del sistema mundo, en la teoría empezó a decaer con dos hechos históricos relevantes: el primero, la caída, o mejor la "tumbada", del Muro de Berlín en noviembre de 1989; el segundo, la expedición de la política exterior de la Perestroika (reestructuración) de Mikhjail Gorbachev, quien llegó al poder de la Unión Soviética en 1985.

Gorbachev, a través de su política de reestructuración, intentó levantar el hundimiento económico de la Unión Soviética encausando su población mediante patrones de comportamientos rígidos y definidos para tal fin. Dicho modelo rígido lo enemistó con las élites burocráticas, sin embargo emprendió sin miramientos la glásnost (democratización). En concordancia, con la democratización formuló y ejecutó una política exterior denominada "nuevo pensamiento", donde ya no importaba tanto el poderío nuclear, sino poseer el mínimo necesario para garantizar la seguridad de la Unión Soviética y la cooperación y el consenso en las relaciones internacionales.

En consecuencia con lo descrito, Gorbachev debilitó al Politburó entre 1987 y 1990, mediante reformas relevantes a las personas de nacio- nalidades no determinantes dentro de la Unión Soviética, se autonombró presidente del Presidium del Soviet Supremo y estableció que una vez terminado su periodo, el líder se denominaría presidente de la República, un cambio de forma y no de fondo. Sin embargo, al ampliarse el sistema político, los conflictos nacionalistas florecieron.

Joseph Nye consideró que "el declive de la economía soviética reflejó una menor capacidad de planeamiento central para responder al cambio económico global... Si bien el poder militar sigue siendo importante, es un error para cualquier país descartar el papel del poder económico y el poder blando. Pero también es un error no tomar en cuenta la importancia de los líderes con valores humanitarios" (2006).

Si bien fueron los pactos económicos de la URSS los que sobrepasaron sus arcas, lo que provocó el principio del fin de la GF, un gran sector de la doctrina consideró que al colapso del esquema soviético se sumaron factores políticos de soft law descritos en las nuevas ideas liberales, que debilitaron la cohesión social que proveía la unión de las viejas naciones. Dichas tensiones identitarias se cultivaban dentro de la uRSS inclusive varias décadas atrás como lo afirmó Charles Tilly.

A través de este repaso breve de la consolidación del sistema mundo bipolar y su terminación con la caída de la uRSs, se pretende iniciar el estudio de caso colombiano, no sin antes enfatizar en las consecuencias de los cambios en la tipología de los enfrentamientos clásicos y con- 
temporáneos que se produjeron en razón de la variación de un mundo bipolar a uno multipolar.

Como demostraremos a continuación, aquellos enfrentamientos clásicos o regulares entre ejércitos regulados -guerras interestatales acompañadas de bloques conformados por alianzas políticas- han dado paso a multitudes de enfrentamientos irregulares o nuevas amenazas, que no necesariamente son ordenadas ni ejecutadas por Estados o sujetos de derecho internacional público, sino por actores internacionales irregulares, como protagonistas de conflictos armados intermésticos, es decir, aquellos que conllevan factores endógenos y exógenos en su creación y mantenimiento histórico-político.

\section{NACIONALISMO DE LA POSGUERRA FRÍA DESPUÉS DEL DERRUMBE DE LA UNIÓN SOVIÉTICA}

En 1991 la uRSs desapareció y con ella el modelo bipolar de la GF que imperó en el sistema mundo desde 1945. A partir de entonces, el sistema mundo se conoce con el nombre de posguerra fría (PF). En esta etapa se generó la necesidad de redefinir la política mundial y su contexto, en teoría menos belicoso.

Juan Gabriel Tokatlián ha denominado a la PF como la necesidad evidente de

configuración de un Nuevo Ordenamiento Internacional diseñado en Occidente y dirigido desde Washington. Existe unanimidad en cuanto a la terminación del enfrentamiento ideológico EsteOeste, pero el final de esa disputa no ha sido sinónimo de equilibrio y estabilidad: puede incluso multiplicarse el desorden y el caos, tanto en el centro como en la periferia, en el pasaje hacia formas de orden más maduras, duraderas e intrincadas... constituye una aspiración ideal más que una realidad (s.f., p. 26).

Según Buzan y Waever (2003, p.s.d), el sistema mundo de la pF debe ser analizado a través de tres teorías:

1. Neorrealismo: estatocentrismo y sus alianzas;

2. Globalista: actores no estatales y aspectos culturales, transnacionales y economía política;

\section{Regionalista: alternativa ecléctica.}

Evidentemente la PF no cuenta con consenso sobre sus etapas. Se produjo una vez concluido el periodo de GF que dominó el sistema mundial del siglo XX y que parecía perpetuo, pues se actuaba bajo una lógica predecible que permitía pronosticar las alianzas políticas, económicas y militares. La cuestión ideológica dominante desapareció como elemento catalizador.

En 1989 Kaplan (citado en Arenal, 2010, p.s.d.) refirió el cambio de un esquema bipolar flexible a un esquema no definido, que permite pensar que a partir de la década del 90 el sistema mundo se caracterizó por la presencia de una unipolaridad norteamericana, manifestada en intervenciones armadas que se extendieron hasta el año 2008, principalmente, lo que desató múltiples crisis nacionalistas. 
No obstante, respecto a la unipolaridad del sistema mundo ha existido un incesante debate teórico, por ejemplo, en cuanto a la consolidación de un sistema multipolar donde no impere la voluntad política de EE. UU., China y Rusia (denominados la tríada del poder político internacional), quienes sumados a la India y la Unión Europea constituyen uno de los principales centros de poder político contemporáneos. Por qué no hablar de Brasil como el país pivote de la escena latinoamericana y uno de los miembros del poderoso BRIcs (sigla del grupo conformado por Brasil, Rusia, India, China y Sudáfrica).

Aunque la mayoría de los norteamericanos se casaron con la teoría de la unipolaridad por la desaparición de la uRss, Henry Kissinger en 1996 publicó su libro Diplomacia, en el cual trató el tema de la gestación del ordenamiento mundial de la pF y definió al sistema mundo como un sistema donde prevalecían "cinco o seis grandes potencias y una multiplicidad de Estados más pequeños... una reconciliación y un equilibrio de intereses nacionales en competencia" (p. 866 y 867).

No obstante, dicho debate supera el objeto de nuestro artículo, por lo cual simplemente exponemos una síntesis de los posibles tipos de configuración respecto a la polaridad en política internacional. En general se distinguen cinco tipos de sistemas: ${ }^{1}$ unipolaridad, bipolaridad, tripolaridad, multipolaridad y no polaridad.

Véase http://centrodeartigos.com/articulos-enciclopedicos/article_87775.html.
Unipolaridad: distribución de poder en la que un Estado ejerce la mayor parte de la influencia cultural, económica y militar (Nuno P. Monteiro, Robert Jervis, Daniel Nexon, Thomas Wright). Ejemplo: EE. UU. único país a principios del siglo XXI, que posee la capacidad de proyectar poder militar en una escala global (Kenneth Waltz, John Ikenberry y Barry Posner).

Bipolaridad: distribución de poder en el que dos Estados tienen la mayor parte de la influencia económica, militar y cultural a nivel internacional o regional. A menudo, las esferas de influencia se desarrollarían conforme al avance de la contraparte.

Tripolaridad: distribución de la decisión de la política internacional en tres centros de poder o Estados. Ejemplo: tríada del poder político: EE. UU., China y Rusia (Kissinger).

Multipolaridad: distribución de poder en el que más de dos Estados-nación tienen cantidades casi iguales de influencia militar, cultural y económica (sistema internacional posterior a 2001).

No polaridad: sistema internacional con numerosos centros de poder en el que ninguno domina. Pueden ser los Estados-nación, las corporaciones, las organizaciones no gubernamentales, los grupos terroristas, etc. La potencia se encuentra en muchas manos y muchos lugares.

Dos obras destacadas sobre el tema de los centros de la política internacional del sistema mundo son la de Francis Fukuyama y la de Samuel Huntintong.

Fukuyama reduce los diversos enfrentamientos a una pugna filosófica de los griegos entre materialismo (comunismo o socialismo tipo URSs) e idealismo (capitalismo o la sociedad liberal). No obstante, distingue dos elementos sueltos: fundamentalismo islámico y nacionalismo, modelos que se pueden aplicar solo en regiones culturales determinadas.

Fukuyama se fundamentó en el liberalismo más allá de los debates ideológicos, concentrándo- 
se en las insuficiencias que representa el enfoque de los sistemas democráticos capitalistas o cualquier modelo que desafíe la dialéctica actividad de cualquier sistema.

Parecía recaer en idealismos utópicos al manifestar que: "Las causas fundamentales de la desigualdad económica no tienen que ver con el substrato legal ni la estructura social de nuestra sociedad. ... La pobreza negra en USA no es el producto inherente del liberalismo, sino más bien el legado de la esclavitud y el racismo que ha persistido mucho después de la abolición formal de la esclavitud" (citado en Huguet, 1991).

Contrariamente se manifestó Samuel Huntington en su obra The Clash of Civilizations and the Remaking of World Order (El choque de las civilizaciones y la reconfiguración del orden mundial), en la cual sostuvo que el asunto primordial de poder no es el económico sino la cuestión nacionalista o civilizatoria, e introdujo como aspecto central la variable cultural trayendo a colación los planteamientos de Braudel, que termina en conflictos fundamentados en los estereotipos que encierran las diversas creencias y valores (occidentales, latinoamericanos, islámicos, japoneses, africanos, hindúes, chinos, budistas, ortodoxos).

Para Huntington la nueva era en la política mundial de la PG se concentrará en conflictos culturales más que en guerras clásicas o interestatales o inter-bloquistas.

Una guerra clásica interestatal, "se conduce en contra del ejército regular de un Estado... y son reguladas por el derecho internacional público... las nuevas guerras, son conducidas por diversos actores muchas veces no estatales sin algún tipo de regulación legal... Las nuevas guerras... (o) guerras incorrectas... son guerras de desintegración del Estado, como consecuencia del fracaso de una estatalidad robusta" (Münkler, 2002, pp. 13-14).

Esto parece ser cierto en el Estado colombiano, donde es evidente la ausencia de guerras clásicas pero donde afloran cada día conflictos armados internos entre diversas ideologías de grupos sociales.

Pero Huntington tal vez no pensó en alianzas como el BRICs, donde culturas extremadamente diversas unen sus esfuerzos para alcanzar intereses comunes y muestran cómo el sistema que se pensó unipolar se convirtió dos décadas después en uno de realidad multipolar. La idea de la occidentalización del sistema mundo arroja uniones que pretenden desmoronarla mediante el reforzamiento de valores que han sido apabullados, en especial, por los actuares estadounidenses.

El principal argumento de la obra conlleva la idea de que la variable cultural reemplaza la estructura económica capitalista o comunista, como elemento catalizador de las ideologías de los pueblos.

Por ejemplo, el Huntington sostuvo que:

Las coaliciones ruso-chinas, así como chinomusulmanas (Ej.: alianza China-Irán-Pakistán), tienen como objetivo contrarrestar el univer- 
salismo occidental. Sin embargo una alianza ruso-musulmana es poco probable, ya que esta última civilización es vista como amenazante por la primera. De entre los alineamientos emergentes, Huntington observa como los más conflictivos, los que existen entre: Japón-Rusia, Africa-Islam, Occidente-China, Occidente-Islam, Hindú-Islam, Hindú-China y Rusia-Islam (Arroyo, 1996, citada en Nomberto 2010).

Igualmente, luego de los atentados del 11 de septiembre se amplió la "gama de intereses de quienes hacen las guerras... grupos ilegales, con raíces o no en viejos conflictos, están armados y están violando los derechos de miles de personas solamente para ganar dinero" (Howland, 2012), como lo demostraremos en el estudio del paramilitarismo colombiano y en especial en el análisis de la masacre de Mapiripán y su contexto interméstico a nivel jurídico-político.

En consecuencia con lo anterior, la seguridad nacional representa la ausencia en teoría de “amenazas y la capacidad de los Estados de mantener su identidad, su independencia, integridad y funcionamiento ante fuerzas hostiles" (Salazar, 2002, p. 186), independientemente del modelo de polaridad que se imprima en las coyunturas sociohistóricas del sistema mundo.

Así, el gran inversionista clásico que siempre era el Estado, comenzó a ser superado por los actores privados transnacionales, violentos o no, que incrementaron ágilmente su poder, conllevando la disminución en la concentración del poder político estatocéntrico. En este sentido vale la pena rescatar los aportes de Saskia Sassen y Niall Fergusson.
En cuanto a lo sostenido por Sassen y la coyuntura de la nueva geografía política, hace presencia un campo mixto público y privado transfronterizo, donde el Estado merma sus “capacidades de regulación, debido a ciertas políticas de base relacionadas con la mundialización económica: desregulación de un conjunto importante de los mercados, de sectores económicos y de límites nacionales, y privatización de firmas del sector público... un proceso de transformación del Estado" (Sassen, 2000).

Por su parte, Fergusson ha manifestado que

alrededor del mundo hay consenso de que tener un sistema mixto y dinámico entre privado y público funciona mejor que un sistema monopólico estatal. Y esto es interesante, porque pareciera que aumentar los servicios entregados por privados incrementa los estándares en países que antes tenían monopolios estatales... es posible tener un desarrollo económico de largo plazo, sostenible y sólido con grandes niveles de desigualdad (Fernández, 2004).

Igualmente coincide Fergusson con Huntington en que el factor cultural principalmente representado en las creencias religiosas es el factor decisivo en la división violenta del sistema mundo. No obstante sostiene que Huntington se equivocó pues “desde 1991 el conflicto no ha sido entre civilizaciones sino en las civilizaciones. Y los mayores conflictos están dentro del islam. La mayoría de los musulmanes que mueren violentamente están siendo asesinados por otros musulmanes" (Fernández, 2004). Así como los colombianos mueren a manos de colombianos. 
A. Condicionamientos de la PF a la política exterior colombiana

Desde 1945 se dejó atrás el modelo clásico de las RR. II., en el cual el uso de la fuerza armada era legítimo para resolver las controversias interestatales o interbloquistas internacionales mediante la declaración de guerras clásicas ejecutadas por los ejércitos de los Estados, únicos sujetos de derecho internacional público.

La nueva escuela de las RR. II. fue denominada escuela contemporánea o escuela institucional. En este modelo que impera en 2014, el uso de la fuerza armada o violencia legítima para resolver controversias internacionales fue prohibido por regla general.

Entendamos por violencia legítima la "realización de un poder acumulado sobre el término más débil de una relación social asimétrica, que se despliega cuando los símbolos y valores que sostienen el poder se ven amenazados. Se presenta como combate entre fuerzas iguales, pero esta imagen encubre historias previas y relaciones de poder" (Arias y Cieza, 2010, p. 3).

Como toda regla general, se estipularon excepciones al uso de la violencia legítima o de la fuerza armada, como cuando medie una resolución expedida por el Consejo de Seguridad de las Naciones Unidas; en caso de intervenciones en catástrofes naturales o humanitarias; y cuando deba utilizarse la fuerza armada para revestir una agresión injustificada bajo los postulados proporcionales de la legítima defensa.
En síntesis, en el esquema clásico la regla general fue la presencia de guerras correctas, regulares o clásicas, mientras que en el actual modelo contemporáneo de las RR. II. abundan las mutaciones de las revoluciones armadas. En especial a partir de la PG, menguaron los enfrentamientos interestatales para dar paso al ciclón de las nuevas guerras, irregulares, gestadas entre actores y sujetos internacionales.

\section{B. Nuevas guerras: el caso del paramilitarismo en Colombia}

En la década del 80 se crearon en Colombia grupos tales como el movimiento mas -Muerte a Secuestradores- motivados por las eficaces agresiones que propiciaban los narcos a los guerrilleros.

La Gobernación de Antioquia, liderada por Álvaro Uribe, una década después mediante el Decreto 356 de 1994, legalizó las Asociaciones Comunitarias de Vigilancia Rural (Convivir), ${ }^{2}$ que permitían armar civiles y coordinar su actividad a través de las Fuerzas Armadas (FF. AA.). ${ }^{3}$

En 1998, Andrés Pastrana revocó la situación en medio de la necesidad de realizar gestos políticos en el marco del naciente proceso de paz con la guerrilla de las Farc.

2 Sus miembros han sido acusados de graves violaciones a los DD. HH. y fueron una base sólida para la expansión del paramilitarismo en Antioquia.

3 A finales de 1997 se habían expedido 400 licencias que permitían las Convivir, financiadas por empresarios que buscaban protegerse. 
Mientras tanto, los dispersos grupos de autodefensa y miembros remanentes de las Convivir se agrupaban en las Autodefensas Unidas de Colombia (AUc), de la siguiente manera:

las Autodefensas de Córdoba y Urabá copan, hacia el norte, las sabanas de la costa Caribe y, hacia el sur, el departamento del Chocó, mientras que las Autodefensas del Magdalena Medio y las del sur del Cesar y Santander avanzan hacia el norte de esta región y llegan a copar los departamentos del Cesar, Bolívar y los Santanderes... dotados de un plan estratégico de aplicación territorial y de un discurso político que los ha llevado a reclamarse como actor político (González, 2003, pp. 63-64).

\section{Recogiendo}

la cosecha de varios años de construcción de un verdadero ejército... no se trataba de grupos armados subordinados a otros poderes, eran ejércitos de combatientes con una doctrina, identidad simbólica (uniformes, escudos, himnos) y armamento de guerra, que garantizaban la primacía de sus jefes sobre el poder local... se hacen llamar autodefensas y niegan su carácter de paramilitares... en las escuelas de formación del Bloque Central Bolívar... repetían a los nuevos reclutas en la clase de formación política: las autodefensas son un grupo político, militar, antisubversivo, al margen de la ley, anticomunista, antiterrorista, que busca la paz del país... Nosotros solo matamos guerrilleros (Duncan, 2005 en Cubides, 2005, p. 110).

Logrando en poco tiempo pasar de dejar de ser vistos como criminales para ser considerados oficialmente como actores políticos, agremiados en una "federación de grupos regionales... de una estructura flexible, efectiva para obtener dividendos de cara al proceso de negociación... con diversidad regional y capacidad de cooptar e integrar a su estructura cualquier grupo... formado como reacción a las acciones de la guerrilla" (Cubides, 2005, p. 109).

Convirtiéndose en una alternativa a un Ejército mermado que no resolvía, militarmente hablando, en contienda antisubversiva. No importaban mucho ni jurídica, ni política, ni social ni mucho menos económicamente, las prácticas terroristas de las Auc.

Muchos sostuvieron que por la anterior minusvalía geoestratégicamente el Estado se fue haciendo el de la vista gorda frente a los valores agregados que le reportaba la presencia de la extrema derecha, generándose, “una relación de dependencia... sin [ellos] el Estado [corría] el riesgo de ser desbordado" (Pizarro, 2006, pp. 116-117).

\section{Factores de reclutamiento paramilitar}

El paramilitarismo tiene creación por varios factores. Unos sostuvieron su constitución por estar

fatigados por los excesos criminales de la guerrilla, tales como el secuestro y la extorsión. Otros fueron impulsados por narcotraficantes como el desaparecido Gonzalo Rodríguez Gacha, para no continuar pagando el impuesto de guerra, el llamado gramaje a las farc. Algunos más, fueron directamente conformados por oficiales del Ejército en el marco de la guerra de contrainsurgencia. Finalmente, otros fueron constituidos por conocidos y controversiales 
líderes de las minas de esmeraldas (Pizarro Leongómez, 2004, p. 121).

Igualmente, al paramilitarismo se le ha considerado desde enfoques divergentes, por ejemplo, como: "una política terrorista impulsada por el Estado, mientras que otros lo miran como tercero en discordia, víctima del fuego cruzado de insurgentes de izquierda y vigilantes de derecha. Finalmente, otros analistas tienden a vincularlos a una especie de gamonalismo armado, que expresaría cierta dislocación del Estado" (González, 2003 p. 59).

En el mismo contexto temporo-espacial, la academia lo consideró

un proyecto político, social y económico con alcances nacionales y diversidades regionales, al vaivén de las coyunturas políticas, de la interacción con sectores sociales determinados y con respecto a las políticas públicas... constituyen, en cuanto actores de la violencia a escala nacional, en irregulares del Estado..., y, simultáneamente, en una modalidad de dominación regional por medio del gamonalismo armado (Palacios, 2206, p. 60).

Por su parte, los sectores de la sociedad civil organizada extragubernamentalmente, denunciaron

una política de Estado... que cuenta con el apoyo y aquiescencia de las FFAA... del poder ejecutivo, por carecer de voluntad política para tomar medidas encaminadas a desmantelar[los]... del poder judicial, al situar las acciones y la investigación sobre los hechos perpetrados por los paramilitares en un plano secundario, que conduce a reforzar los mecanismos de impunidad (González, 2006, p. 59).

Del legislativo, sobornando políticos para influir en la formulación de las leyes, así como el uso y la amenaza del uso de la violencia y del terror, en cuanto a las elecciones se refiere.

La línea difusa de la estatalidad de los paramilitares ha sido en varias ocasiones develada por los fallos de Cortes norteamericanas ${ }^{4}$ y colombianas, donde se les ha atribuido la condición estatal, ${ }^{5}$ y de la misma manera, actores claramente identificables como estatales han sido juzgados desde su condición clandestina paramilitar.

Así, a través del uso de paramilitares se facilitó "la instalación del Estado modernizante, con el concurso del sector privado" (González, 2006, p. 62), a la vez que estos se financiaron con el narcotráfico y con "un ingreso continuo y calculable sobre una base tributaria clara: los recursos obtenidos de quienes quieren comprar seguridad. A todo esto se añade un sistema de recaudación de contribuciones más o menos forzadas, que no obstante, son predecibles" (Cubides, 2005, p. 75).

Adicionalmente, los cambios de la política estatal y exterior norteamericana a raíz de los atentados del 2001, propiciaron que el Departamen-

\footnotetext{
4 El 14 de 1 bril de 2003 se admitió una demanda presentada por la Fundación Internacional para los Derechos Laborales en nombre del sindicato de mineros y familiares de los asesinados ante una Corte laboral en Alabama, EE. UU.

5 Demanda por conspiración con paramilitares para asesinatos sindicales en marzo de 2001
} 
to de Estado norteamericano, clasificara a las AuC dentro de la lista de los grupos terroristas y la posibilidad de su extradición a los EE. UU.

El gobierno indicó que "hasta un $80 \%$ de la financiación de las Auc provenía del narcotráfico y que se había hecho imposible diferenciar entre paramilitares y narcotraficantes" (López, 2005, p. 222).

Ante el escenario violento de 2002, el entonces presidente Uribe Vélez revivió a las Convivir creando una la red de cooperantes que actuaba igualmente bajo la dirección de las FF. AA., con el fin de "vigilar permanentemente a sus vecinos e informar a las autoridades... cualquier circunstancia o persona sospechosa, según el criterio de cada informante... a cambio... reciben recompensas... asignan[do] a las personas civiles funciones de inteligencia militar" (Gallón, s.f., pp. 129-130).

Concomitantemente lideró la creación de la figura jurídica de los soldados campesinos, "como un medio adicional de penetración territorial" (Pizarro, 2006, p. 305), vulnerando los estándares normativos internacionales del principio de distinción.

La Ley de Justicia y Paz, (Ley 975 de 2005), es el resultado de la negociación política que se gestó en Santa Fe de Ralito, donde gobierno y paramilitares sobrepusieron las variables políticas y económicas a los postulados básicos de la variable jurídica, que produjo un acuerdo de pena máxima de ocho años de prisión a criminales de lesa humanidad.
Una vez que las Auc anunciaron el cese al fuego unilateral, se "designó una comisión exploratoria para un eventual diálogo de paz... el 13 de marzo de 2003 culminó... la fase de acercamiento entre la comisión gubernamental y... Carlos Castaño y Salvatore Mancuso y se inició la etapa siguiente llamada de negociación... para incorporar alrededor de ocho mil combatientes" (Pizarro, 2006, p. 309).

El 15 julio de 2003, "se firmó el Acuerdo de Santa Fe de Ralito... acordaron lograr la paz nacional, casi con un dictado internacionalista buscando el fortalecimiento de la gobernabilidad democrática y la recuperación del monopolio de la fuerza" (Echandía, Bechara y Cabrera, 2010, p. 91).

Una poesía terrorífica declamada por algunos descuartizadores y violadores, en compañía de los representantes políticos de los colombianos. Mancuso fue aplaudido en el Congreso de la República.

Gestando a la descarada parapolítica como la mezcla de miembros como narcos, paras y políticos en una agremiación de tinte ideológico de extrema derecha. El sistema político dispuesto en el mercado amoral y antiético, comercializado al mejor postor.

Desde el proceso de desmovilización los paramilitares han desparecido del discurso político y de seguridad. Se lanzó la idea y la orden de concebir a los grupos narcoviolentos como meros grupos de crimen organizado desligados de cualquier conexión estatal. 
Han sido denominados Bacrim, y su reducción corresponde ahora a la Policía Nacional y no a las Fuerzas Militares. No obstante el cambio de enfoque, el riesgo sigue latente.

Las Bacrim siguen llenando los narco-hoyos, funcionando en torno a "la disputa por el control del narcotráfico... [las más importantes] Los Urabeños, Los Paisas, Los Machos, Renacer, Ejército Revolucionario Popular Anti-subversivo de Colombia (Erpac) y Los Rastrojos... estas estructuras tienden a recomponerse rápidamente, reemplazando a los miembros" (Niño, 2011, p. 168).

Según el mensaje oficial interno e internacional, ya no son más una organización terrorista, sino por el contrario, estos grupos de crimen organizado no revisten peligro a la seguridad interna ni internacional porque en teoría no ostentan intereses políticos, sino la cooptación territorial del Estado para sus negocios ilícitos y prestando servicio de seguridad privada a empresas nacionales o multinacionales. Sin embargo, la clasificación teórica de ser grupos no estatales, encuentra opositores pues el paramilitarismo sigue inserto en el sistema político.

\section{Factor exógeno como predominante político externo: asimetrías marcadas por la posguerra}

El narcoterrorismo se originó conceptualmente en escenarios políticos estadounidenses, cuya dimensión teórica se torna esquizofrénica mediante la "convergencia entre narcotráfico y terrorismo" (Pizarro, 2006, p. 135).
La ambivalencia conceptual remarca la asimetría práctica y en especial política de las RR. II., facultando políticamente a los Estados centrales, poderosos o desarrollados para liderar los procesos internacionales multilaterales conforme la parametrización jurídica seudoobligatoria frente a sus débiles Estados periféricos y subdesarrollados.

La narcoviolencia es la violencia resultante de los grupos narcotraficantes. Este concepto elimina la posibilidad de convertibilidad política que representa el terrorismo o la práctica de actos terroristas, propiciando el terrorismo político como garantía, pues "los gobernantes utilizan las maquinarias del Estado legítimamente constituido para ejercer violencia ilegítima contra sus enemigos" (Prieto, 2003, citado en Zeraoui, 2008, p. 288).

El terrorismo perpetuado por los grupos de extrema derecha no pretende desagregar el Estado, por el contrario, trata de reforzar la presencia de este, por lo cual no se entiende muy bien si es terrorismo de extrema derecha o simplemente es un terrorismo de Estado.

Los vínculos son de difícil comprobación, porque el Estado es quien detenta el poder, y si el terror lo beneficia, omitirá su persecución legítima. Una estructura para-estatal consolidada y productiva.

Recordemos que el terrorismo de Estado puede operar y activarse "directamente, por medio de agencias del Estado mismo, o indirectamente, mediante la utilización de entidades sustitu- 
tas, como otros Estados o grupos o individuos" (Shulz en Zeraoui, 2011, p. 7).

\section{COOPERACIÓN MILITAR FRENTE A LAS NUEVAS AMENAZAS}

Las multinacionales petroleras instaladas en el territorio cafetero, los fabricantes de armas, las sociedades militares privadas y otros actores de la élite política-económica norteamericana, invirtieron alrededor de

seis millones de dólares en lobby para lograr que el Congreso estadounidense aprobará el Plan Colombia... sobre los 1300 millones de dólares asignados al Plan Colombia por Estados Unidos se gastaron 1130 millones sin que un solo funcionario colombiano vea un céntimo. Hasta las sumas provenientes del Banco Mundial para ese Plan serán canalizadas desde Washington hacia las SpM" (Calvo, 2005 en Azzelini y Kanzleiter, 2005, p.s.d.).

Así, EE. UU. importó a Colombia su doctrina de ataques preventivos

recurriendo a una forma moderna de mercenarismo... empleados que pagan impuestos y trabajan en empresas de seguridad que a su vez firman regulares contratos con el Departamento de Estado y son controladas en relación a los términos del contrato firmado... son ex militares que manejan alta tecnología y que... se reciclan dentro del mismo sector, esta vez no estatal, sino privado. Es la tercerización de la guerra, que permite... no poner tantos muertos en los conflictos y no tener que rendir cuenta por ellos (Rossi, 2009, p. 118).
Los paramilitares en sus audiencias jurídicas han denunciado, como lo relató la voz de $\mathrm{HH}$, que las masacres fueron acordadas con altos funcionarios del sistema político colombiano para bajar los índices de muertes dolosas en Colombia, y reportar positivos frente a los sujetos internacionales.

Se confesó la multiplicación del uso de fosas comunes, hornos crematorios, tigres, cocodrilos, descuartizamientos y uso de químicos como ácidos, para borrar del mapa a seres humanos, la mayoría de las veces ajenos al conflicto y de extracción humilde.

A pesar de que EE. UU. en 2011 aportó a Colombia fondos de asistencia por aproximadamente US\$562 millones, y cerca del 61\% se destinó a ayuda militar y policial (Human Rigths Watch [HRW], 2012, pp. 31-32), del énfasis de seguridad y defensa de los últimos gobiernos colombianos en la formulación y gestión de sus políticas públicas y por ende en el desarrollo legislativo de sus marcos normativos, el señalamiento jurídico internacional al Estado aumenta, pero sus acercamientos políticos merman las consecuencias jurídicas al igual que los estándares soberanos.

El escenario internacional representa un salvavidas para los ciudadanos de sistemas jurídicos corruptos y violadores de derechos humanos (DD. HH.). A pesar de los sinsabores que deja el sistema jurídico nacional e interamericano sobre la verdad real y su reflejo en la verdad procesal, se produce un verdadero control de convencionalidad en cuanto se refiere a crímenes internacionales. 
Veamos la influencia de la política exógena sobre marcos jurídicos soberanos y del Sistema Interamericano de Derechos Humanos (SIDH), a través del estudio de la masacre de Mapiripán, que fue concebida por los paramilitares como un genocidio pues asesinaron a los pobladores por ser auspiciadores de la guerrilla, bajo la teoría política de amigo-enemigo y donde el Estado colombiano participó activamente.

Aclarando que existen, como este, muchos hechos aberrantes similares, su repaso nos mostrará cómo el sistema mundial ha cambiado en cuanto a la complementariedad o subsidiariedad de los sistemas jurídicos internacionalizados, previa manifestación de los Estados a adherirse a ciertos tratados, pero lo cierto es que en las relaciones asimétricas, el Estado de la periferia claramente está condicionado a otros Estados centrales.

Estados Unidos representa para Colombia su condicionante externo, y esto, le reporta ventajas y desventajas a la soberanía. Ventajas pues se escuda frente a terceros y el grado de atención es bajo cuando no representa una confrontación a sus intereses nacionales. Desventajas cuando el Estado le representa controversia.

\section{SUBSIDIARIEDAD DE LA JUSTICIA INTERAMERICANA}

La Corte Interamericana de Derechos Humanos (Corte IDH) creó el concepto de control de convencionalidad que "plantea alternativas para el control judicial interno de convencionalidad... implica la consulta sobre convencionalidad de normas elevadas a un tribunal superior competente para atender y resolver la consulta [conllevando] la armonización de la jurisprudencia nacional y evitando la multiplicación de decisiones judiciales discrepantes" (García Ramírez, 2011, p. 28).

El control de convencionalidad no fue adoptado originalmente dentro del marco jurídico internacional del SIDH, y como señalan Rey, García y Gonzaini (2008, pp. 81-90), se debió al ocurrir un cambio de jurisprudencia del caso Suárez Rosero vs. Ecuador (Corte IDH, 1997) ${ }^{6}$ al caso Castillo Petruzzi y otros vs. Perú (Corte IDH, 1999).

La primera vez que se utilizó el concepto en la práctica fue en 2003, en el caso Myrna Mack Chang vs. Guatemala, y dentro del sIDH ocurrió el 26 de abril de 2006 cuando la Corte IDH falló el caso Almonacid Arellano vs. Chile, de la siguiente forma: "los jueces y tribunales internos están sujetos al imperio de la ley y, por ello están obligados a aplicar las disposiciones vigentes en el ordenamiento... cuando un Estado ha ratificado un tratado... también están sometidos a ella" (sentencia de 25 de noviembre de 2003).

El control de convencionalidad, en primera instancia, es aplicado a través de las actividades realizadas por los “judiciales domésticos, haciendo una comparación entre el derecho local y el supranacional, a fin de velar por el efecto útil de los instrumentos internacionales, sea

6 Véase también el voto razonado del juez Cancado Trindade en el caso "La Última Tentación de Cristo" (caso Olmedo Bustos y otros vs. Chile, sentencia de 5.22001 , serie $\mathrm{C} n .^{\circ} 73$, párr. 13). 
que surja de los tratados, del lus Cogens o de la jurisprudencia de la Corte IDH; y luego esa tarea debe ser ejercida por (ella), si... el caso llega a sus estrados" (Hitters, 2009, p.s.d). Su aplicación subsidiaria procede de oficio.

La masacre ocurrió en 1997 y en 2005 el Estado colombiano aceptó ser responsable de ella. La precaria actuación judicial omitió establecer el número exacto de personas masacradas. Las víctimas fueron descuartizadas y lanzadas al río Guaviare. En ese mismo año la Corte IDH condenó a Colombia a reparar a los familiares de las víctimas, entre otras medidas.

Pero en el 2011, el Estado colombiano denunció que reparó a falsas víctimas. En 2014 tal denuncia no ha terminado en acciones judiciales concretas más que en críticas mediáticas y políticas frente a las decisiones adoptadas por la Corte IDH.

Para poder determinar los diversos escenarios jurídicos nacionales e internacionales, es preciso comenzar recordando rápidamente el SIDH, así como las condiciones de tiempo, modo y lugar que acompañaron tan funesta orgía terrorista.

\section{A. SIDH: mecanismo de promoción y protección de los DD. HH.}

Su ámbito de aplicación está destinado a todos los nacionales de los Estados americanos, víctimas de las garantías fundamentales principalísimas para obligar a los Estados violadores de IOS DD. HH. a reparar a sus víctimas.
La estructura jurídica principal cuenta con dos pilares autónomos y fundamentales de la Organización de Estados Americanos (OEA):

1. La Comisión Interamericana de Derechos Humanos (CIDH) con sede en Washington D. C.; y

2. La Corte Interamericana de Derechos Humanos (Corte IDH) con sede en San José de Costa Rica. Sus bases normativas descansan en la Declaración Americana de los Derechos y Deberes del Hombre (1948), primer documento internacional de derechos humanos de carácter general; en la Carta de la oEA (1948) y en la Convención Americana sobre Derechos Humanos $(\mathrm{CADH})^{7}$ firmada en 1969 y vigente desde 1978.

Los Estados miembros de la OEA son: Antigua y Barbuda, Argentina, Bahamas, Barbados, Belice, Bolivia, Brasil, Canadá, Colombia, Costa Rica, Chile, Dominica, Ecuador, El Salvador, Estados Unidos, Grenada, Guatemala, Guyana, Haití, Honduras, Jamaica, México, Nicaragua, Panamá, Paraguay, Perú, República Dominicana, Saint Kitts y Nevis, Santa Lucía, San Vicente y las Granadinas, Suriname, Trinidad y Tobago, Uruguay y Venezuela.

La CADH, a 2013, ha sido ratificada por 25 países: “Argentina, Barbados, Brasil, Bolivia, Chile, Colombia, Costa Rica, Dominica, República Dominicana, Ecuador, El Salvador, Granada, Guatemala, Haití, Honduras, Jamaica, México, Nica-

7 En noviembre de 1969 se celebró en San José de Costa Rica la Conferencia Especializada Interamericana sobre DD. HH. Los Estados miembros de la OEA convinieron la CADH, Convención que entró en vigor el 18 de julio de 1978, al haber sido depositado el undécimo instrumento de ratificación. 
ragua, Panamá, Paraguay, Perú, Suriname, Uruguay, Venezuela" (OEA, s.f.) y Trinidad y Tobago.

\section{B. Comisión Interamericana de Derechos Humanos (CIDH)}

Compuesta por siete expertos en DD. HH. que actúan a título personal y no en representación de sus Estados de origen, elegidos por meritocracia en Asamblea General de la OEA, de un listado presentado por los Estados miembros; no es posible que existan dos representantes de la misma procedencia nacional.

Fue creada como órgano consultivo mediante la Resolución de la Quinta Reunión de Consulta de Ministros de Relaciones Exteriores en Santiago de Chile (1959), se reunió por primera vez en 1960, y busca promover y proteger el ámbito de IOS DD. HH.

Cada comisionado gestiona por cuatro años con posibilidad de reelección por un período igual. Sus funciones más importantes son:

\section{Funciones aplicadas a Estados miembros}

Estimular la conciencia de los DD. HH. en los pueblos de América.

Formular recomendaciones a los gobiernos para que adopten medidas progresivas en favor de los DD. HH.

Preparar estudios e informes, programas-presupuestos.

Solicitar a gobiernos informes sobre DD. HH.

Atender las consultas que, por medio de la Secretaría General de la OEA, le formulen.

Practicar observaciones in $10 \mathrm{co}^{8}$ en un Estado, con la anuencia o a invitación del gobierno.
Funciones aplicadas a Estados miembros de la CADH

Diligenciar peticiones y otras comunicaciones.

Comparecer ante la Corte IDH en los casos previstos.

Solicitar a la Corte IDH medidas provisionales en asuntos graves y urgentes que aún no estén bajo su conocimiento.

Consultar a la Corte IDH acerca de la interpretación de la Convención o de otros tratados regionales sobre DD. HH.

Someter a la consideración de la Asamblea General de la OEA proyectos de protocolos adicionales.

Someter a la Asamblea General de la OEA propuestas de enmienda a la Convención.

Funciones aplicadas a Estados miembros que no son partes de la $\mathrm{CADH}$

Observancia de los DD. HH.

Examinar comunicaciones que le sean dirigidas y dirigirse a los gobiernos para obtener informaciones pertinentes y formular recomendaciones.

Verificar si los procesos y recursos internos fueron debidamente aplicados y agotados.

\section{Corte Interamericana de Derechos Humanos}

Órgano autónomo judicial de la oEA que interpreta la CADH y otros tratados de DD. HH., a los cuales se somete el SIDH.

Trabaja oficialmente en español, francés, inglés y portugués, con siete jueces elegidos por meritocracia y no por representación de los Estados miembros de la OEA, sin que se repitan nacionalidades. Su período de actividad transcurre durante siete años con posibilidad de una única reelección.

El 20 de julio de 1979 inició funciones oficiales en Washington, D. C., y su instalación fue posteriormente llevada a cabo en San José de Costa 
Rica. En la sesión n. ${ }^{\circ}$ 9, la Asamblea General de la OEA aprobó su Estatuto y en 1980 el Reglamento Interno que fue reformado en 2009.

Adicionalmente, en 1980 se creó, con sede en San José de Costa Rica, el Instituto Interamericano de DD. HH. mediante convenio entre la Corte IDH y Costa Rica, entidad que busca promover académica e investigativamente los DD. HH., haciendo hincapié en las enfermedades crónicas de la región. Este Instituto apoya al SIDH en la protección a los DD. HH. Las principales funciones de la Corte IDH, dentro de su competencia contenciosa y consultiva, son:

Corte Interamericana de Derechos Humanos - Funciones

1. Competencia contenciosa

Estados miembros de la OEA que han ratificado la CADH.

Tiene competencia en casos relativos a interpretación y aplicación de las disposiciones de la Convención, siempre que los Estados partes hayan aceptado la competencia.

Conoce casos de vulneración de un derecho o libertad protegidos por la Convención, siendo necesario el agotamiento de los recursos internos.

Las personas, grupos o entidades que no son Estados no tienen capacidad de presentar casos ante la Corte, pero sí pueden recurrir ante ella. La Comisión puede llevar un asunto ante la Corte, siempre que el Estado cuestionado haya aceptado su competencia. La CIDH siempre comparece ante la Corte.

El procedimiento contradictorio termina con sentencia motivada, obligatoria, definitiva e inapelable y en los debidos casos llevará los salvamentos respectivos.

En caso de duda sobre el sentido o alcance del fallo, la Corte lo interpretará a solicitud de cualquiera de las partes, si se solicitó dentro de los 90 días siguientes a la notificación de la decisión.
2. Competencia consultiva

Los Estados miembros de la OEA pueden consultar a la Corte acerca de la interpretación de la CADH o de otros tratados de DD. HH. regionales. Así mismo, pueden consultarla, en su especialidad, los órganos de la OEA.

A solicitud de un Estado miembro de la OEA, puede dar opiniones sobre la compatibilidad entre leyes locales y tratados.

La Corte IDH ha sido blanco de críticas, en especial, por su politización (García y Verdugo, 2011).

\section{Condiciones de facto en Mapiripán (julio 15-20 de 1997)}

El 12 de julio de 1997 despegaron desde aeropuertos militarizados de Necoclí y Apartadó, en el Urabá antioqueño, dos aviones cargados de paracos, armas y municiones, que minutos más tarde aterrizaron en otro aeropuerto militarizado, policial y con batallón antinarcóticos, en San José del Guaviare, Meta.

La Fiscalía informó que el Ejército permitió el uso de sus pistas de aterrizaje y no impidió el abordaje de camiones por parte de los paramilitares, pues según las audiencias jurídicas donde se manifestaron los hechos, se confirmó que el mismo 15 de julio de 1997 el general Jaime Humberto Uscátegui Ramírez, recibió del mayor Hernán Orozco Castro, comandante de la VII Brigada, un comunicado oficial informando los posibles hechos. En el Urabá, el general Rito Alejo del Río, amigo cercano de Álvaro Uribe, coordinó el embarque.

Esa noche los paramilitares durmieron en la misma Inspección de Policía de Charras, e in- 
formaron en la plaza central que habían llegado para asesinar a todo colaborador de la guerrilla de las Farc.

El 15 de julio, ya en Mapiripán, masacraron y violaron durante cinco días a humildes pobladores y niños indefensos. Asumieron el control de las comunicaciones y de las instituciones.

Los actores materiales fueron Salvatore Mancuso, Vicente Castaño, Cumbia, y cuarenta a sesenta paramilitares a su mando, dentro de la estructura terrorista. Sin embargo, quedan dudas sobre la autoría intelectual de la masacre. Por ejemplo, se comprobó durante las audiencias de Justicia y Paz, en el proceso contra "el ex paramilitar Humberto Victoria Oliveros, alias ‘Don Raúl'... que un grupo de ganaderos financiaron con 50 millones de pesos la masacre" (Ganaderos financiaron, 2012).

Las etapas de investigación y juzgamiento realizadas en Colombia fueron objeto de duras críticas nacionales e internacionales. Entre ellos, el abogado de las víctimas, Luis Guillermo Pérez, ${ }^{9}$ mediante acción de tutela logró que los militares implicados fueran objeto de juicio por parte de la justicia ordinaria, pues su trámite en un inició ocurrió respetando el fuero militar, en la justicia especial.

La falta de determinación del número exacto de las víctimas es responsabilidad del Estado, en aquella época, por parte de la Unidad Nacional de DD. HH. de la Fiscalía General de la Nación.

9 Miembro del Colectivo de Abogados José Alvear Restrepo.
Sin embargo, declaró como víctimas a personas que no lo eran. Las falsas víctimas fueron reconocidas como tales por el Estado el 4 de marzo de 2005, y previamente por sus tribunales nacionales penales, disciplinarios y contenciosos.

\section{Mapiripán en el SIDH}

El 6 de octubre de 1999 el Colectivo de Abogados “José Alvear Restrepo” (el Colectivo) y el Centro por la Justicia y el Derecho Internacional, denunciaron la masacre en procedimiento jurídico internacional ante la $\mathrm{CIDH}$.

El 22 de febrero de 2001, en sesión n. ${ }^{\circ} 110$, la CIDH aprobó el Informe de Admisibilidad n. ${ }^{\circ}$ 34/01, conforme a lo establecido en los artículos 46 y 47 de la CADH. El 9 de marzo de 2001 la CIDH instó a las partes, sin éxito alguno, a llegar a una solución amistosa. El 8 de febrero de 2002 adoptó medidas cautelares a favor de testigos en el proceso judicial. El 12 de abril del mismo año dictó medidas cautelares al teniente coronel Hernán Orozco Castro, quien se desempeñaba como comandante interino del batallón "Joaquín París" cuando se produjo la masacre.

El 4 de marzo de 2003, en sesión n. ${ }^{\circ} 117$ y de acuerdo con el artículo 50 la cIDH aprobó el Informe de Fondo n. ${ }^{\circ} 38 / 03$, y concluyó la responsabilidad internacional del Estado:

Colombia es responsable por la violación de los derechos a la vida, integridad y libertad personales de las víctimas de la masacre... del derecho al debido proceso y la protección judicial de las víctimas y sus familiares, previstos en los artículos 8 y 25 de la Convención Americana, 
así como del incumplimiento de su obligación de asegurar el respeto de los derechos previstos en dicho Tratado, en virtud de su artículo 1

y procedió a formularle recomendaciones, cuya naturaleza jurídica no conlleva obligatoriedad pero sí el sometimiento del caso ante la Corte IDH.

El 5 de junio de 2003 la CIDH remitió al Estado el mencionado Informe y le otorgó un plazo de dos meses para que comunicara las medidas que adoptaría y se sirviese manifestar su posición acerca del posible sometimiento del caso ante la Corte IDH, notificando a los peticionarios el informe y solicitándoles comunicar su posición respecto del posible sometimiento del caso a la Corte IDH. El 9 de julio de 2003 los peticionarios confirmaron su intención del juzgamiento de la Corte IDH. El 22 de agosto de 2003, después de dos prórrogas otorgadas por la $\mathrm{CIDH}$, Colombia informó acoger las recomendaciones formuladas.

La CIDH presentó la demanda ante la Corte IDH el 5 de septiembre de 2003, conforme los artículos 50 y 61 de la CADH, fundándose en la denuncia radicada bajo el $n .{ }^{\circ} 12.250$ por su Secretaría el 6 de octubre de 1999. Los fundamentos de derecho, objeto de investigación, pueden sintetizarse en los siguientes artículos: 1.1 (obligación de respetar los derechos); 4 (vida); 5 (integridad personal); 7 (libertad personal); 8.1 (garantías judiciales); 19 (niños); 22 (circulación y residencia); y 25 (protección judicial).

La Corte confirmó su competencia de acuerdo con los requisitos establecidos en el artículo 62.3 de la $\mathrm{CADH}$, argumentando que el Estado co-
Iombiano es miembro de dicha Comisión desde el 31 de julio de 1973 y reconoció la competencia contenciosa de esta el 21 de junio de 1985. El 28 de octubre de 2003 la Secretaría, previo examen preliminar del presidente de Colombia al texto de la demanda, notificó a las partes los plazos de contestación y de designación de representantes jurídicos. Adicionalmente, comunicó al Estado sobre su derecho de designar un juez ad hoc.

El 26 de enero de 2004, los representantes presentaron su escrito de solicitudes, argumentos y pruebas. Por su parte, el 2 de abril de 2004 el Estado presentó su escrito de excepciones preliminares, contestación de la demanda y de observaciones a las solicitudes y argumentos. El 19 de mayo de 2004 la CIDH y los representantes presentaron sus alegatos escritos sobre las excepciones preliminares. El 28 de mayo de 2004 Colombia presentó un escrito de réplica a las observaciones, que el presidente de la $\mathrm{CIDH}$ resolvió no aceptar pues se trataba de un acto procesal que no estaba previsto dentro del trámite jurídico internacional.

El 26 de enero de 2005 los representantes solicitaron, conforme al artículo 45 del Reglamento de la Corte, ordenar al Estado suministrar toda la información correspondiente a las diversas diligencias probatorias surtidas internamente. El 28 de enero de 2005 el presidente de la CIDH expidió resolución de conformidad con los artículos 44 y 47.3, requirió a testigos y otorgó plazo improrrogable de siete días a la CIDH y al Estado, para que presentaran sus observaciones. Además, convocó a los interesados a audiencia 
pública para el 7 de marzo de 2005 y ordenó al Estado suministrar la información requerida.

La Corte dictó sentencia sobre los hechos reconocidos, ${ }^{10}$ declaró continuar con el conocimiento sobre hechos ocurridos no abarcados en el reconocimiento de responsabilidad formulado por el Estado, prosiguió con la audiencia pública fondo, reparaciones y costas, y escuchó los testimonios y el peritaje.

El 8 de abril de 2005 el Estado, la Comisión y los representantes presentaron sus alegatos finales escritos. Así mismo, presentaron amicus curiae: $^{11}$ el 9 de mayo de 2005 la Fundación Manuel Cepeda Vargas, el 15 de mayo de 2005 el Centro Internacional por la Justicia Transicional y el 30 de agosto la Fédération Internationale des Ligues des Droits del'Homme.

La Resolución 23 de la sentencia del 15 de septiembre de 2005 de la Corte IDH declaró por unanimidad que el Estado violó los fundamentos de derecho invocados por los peticionarios y debía, entre otras medidas: determinar la responsabilidad intelectual y material de los autores y colaboradores o auspiciadores; individualizar e identificar, en un plazo razonable, a las víctimas ejecutadas y desaparecidas, así como a sus familiares y garantizar sus condiciones de seguridad, al igual que a los otros expobladores de Mapiripán, que se hubieran visto desplazados,

10 Cfr. Caso de la "Masacre de Mapiripán". Excepciones Preliminares y Reconocimiento de Responsabilidad. Sentencia de 7 de marzo de 2004. Serie C-122. Un paso hacia el cumplimiento de sus obligaciones internacionales.

11 Memoriales ante órganos judiciales nacionales o internacionales que aportan argumentos a favor de una posición. y puedan regresar a Mapiripán, en caso de que así lo deseen; construir un monumento ${ }^{12}$ apropiado y digno para recordar los hechos; implementar programas de educación en DD. HH. y DIH permanentes en las FF. AA.

\section{Mapiripán después del SIDH}

Dentro de los trámites de la polémica Ley de Justicia y Paz, atentatoria del derecho internacional y local, pero campantemente vigente, se conocieron las falsas víctimas indemnizadas. La Corte supervisa el cumplimiento íntegro de la sentencia y da por concluido el trámite jurídico solo cuando Colombia cumpla cabalmente lo ordenado. En cuanto a las reparaciones, se ordenó al Estado que "individualice e identifique las víctimas ejecutadas y desaparecidas, así como sus familiares... tomando en cuenta normas pertinentes [como el] Manual onu sobre la Prevención e Investigación Efectiva de Ejecuciones Extrajudiciales, Arbitrarias y Sumarias" (Caso de la masacre de Mapiripán vs. Colombia, párr. 305).

Por su parte, la Resolución 1/03 dictaminó sobre juzgamiento de crímenes internacionales que:

los estados deben considerar que los crímenes internacionales -tales como el genocidio, los crímenes de lesa humanidad... de guerra (y agresión) - aun cuando atañen a toda la comunidad internacional por su gravedad, afectan principalmente al estado... por tal motivo el

12 Este ha sido muy criticado pues no lleva nombres, específicamente, para evitar controversias por indeterminación de las víctimas. 
principio de territorialidad debe prevalecer en caso de conflicto de jurisdicciones. Asimismo... exhorta a los estados a que adopten las medidas necesarias para considerar estos crímenes internacionales como delitos que dan lugar a extradición".

El Estado informó en 2007 a la Corte IDH que existía incertidumbre acerca de dos casos de reparación por personas que se habían hecho pasar por víctimas. La Corte IDH el 26 de noviembre de 2008 le informó al Estado que tuvo conocimiento de esos hechos desde 2002, pero que sin embargo solo notificó de estos hasta después de fallado el caso mediante sentencia o resolución, y sostuvo que el Estado no puede alegar los nuevos hechos en la etapa de supervisión. Estimó que el SIDH juzga fundamentándose en los hechos y pruebas aportadas por las partes y recordó que cuando ocurren violaciones a los DD. HH. el Estado está obligado a investigar y no puede trasladar la carga de investigación a las víctimas ni a sus representantes.

El Estado denunció en 2011 fraude en la sentencia condenatoria de la Corte IDH por el conocimiento de al menos doce falsas víctimas de las veinte reparadas. Personas que se habían declarado desaparecidas o muertas en la masacre, aparecieron vivas o murieron en circunstancias ajenas. Algunos casos:

\begin{tabular}{|l|l|l|l|}
\hline $\begin{array}{c}\text { Beneficia- } \\
\text { rio }\end{array}$ & $\begin{array}{c}\text { Millones } \\
\text { pesos }\end{array}$ & $\begin{array}{c}\text { Hecho } \\
\text { alegado } \\
\text { Mapiripán }\end{array}$ & \multicolumn{1}{|c|}{ Hecho real } \\
\hline $\begin{array}{l}\text { Familia } \\
\text { Pinzón }\end{array}$ & 258 & $\begin{array}{l}\text { Asesinato } \\
\text { Jaime } \\
\text { Riaño }\end{array}$ & Falleció 1989. \\
\hline $\begin{array}{l}\text { Wilson } \\
\text { Molina }\end{array}$ & 395 & $\begin{array}{l}\text { Su propio } \\
\text { asesinato }\end{array}$ & $\begin{array}{l}\text { Desplazado en } \\
1999 \text { y en 2003 } \\
\text { realizó cambio } \\
\text { de cédula. }\end{array}$ \\
\hline $\begin{array}{l}\text { Mariela } \\
\text { Contreras }\end{array}$ & 1.751 & $\begin{array}{l}1 \text { asesina- } \\
\text { to; } 2 \text { des- } \\
\text { parecidos }\end{array}$ & $\begin{array}{l}\text { Muerte anterior } \\
\text { a los hechos y } \\
\text { de los desapa- } \\
\text { recidos uno fue } \\
\text { dado de baja por } \\
\text { las Farc y el otro } \\
\text { se desmovilizó } \\
\text { de la guerrilla en } \\
2008 .\end{array}$ \\
\hline
\end{tabular}

La señora Contreras denunció en instancias nacionales e internacionales y fue reparada por el Estado por el asesinato de un familiar y la desaparición de otros dos de los suyos, dentro de los hechos ocurridos en Mapiripán. Posteriormente de recibir casi 2000 millones de pesos, “admitió en audiencia que la desaparición de sus dos hijos y la muerte de su esposo, ocurrieron en circunstancias ajenas a la masacre... su esposo fue asesinado por guerrilleros antes de $1997 \ldots$ uno de los hijos... realmente estuvo militando desde 1995 hasta el 2008 en la guerrilla" (Fiscalía denuncia falsos, 2011). A pesar de sus contradictorias y comprobadas declaraciones, acusa al Colectivo de Abogados José Alvear Restrepo (CCAJAR) de ser brazo jurídico de las Farc, afirma que "Ios abogados se aprovecharon de su ignorancia" (Los abogados negociaron, 2011), y sostiene que no conocía sobre el trámite de "demanda por una indem- 
nización... creía que ellos buscaban a la gente, y eso era lo único que... quería" (Los abogados negociaron, 2011).

El colectivo ha manifestado que su actuación como defensores de los DD. HH. "se basó en las declaraciones de las víctimas y las decisiones de tribunales nacionales a nivel penal, disciplinario y contencioso administrativo, que fueron tenidas en cuenta por el Estado de Colombia para reconocer el 4 de marzo de 2005, su responsabilidad internacional por la Masacre" (CCAJAR: comunicado, 2011). "Ella nos dio su versión... y... la sostuvo ante la Fiscalía... Si ella ahora dice que no fue víctima... es ella quien debe aclarar sus actuaciones ante la Justicia y el Estado tendría que proceder a demandarla por falso testimonio" Redacción Justicia, 2011). Frente a los nuevos hechos, el 26 de octubre del 2011 el Colectivo acusó a la Fiscalía General por omisión en la identificación de cadáveres que generaron las falsas denuncias. Adicionalmente, han manifestado devolver el dinero recibido por honorarios, solicitando número de cuenta para consignar, sin embargo, el Estado se ha rehusado a recibirlo. El Colectivo denunció el hecho ante la Procuraduría.

No obstante, este entramando de negras actuaciones no debe esconder la realidad macabra de la situación violenta en el Estado colombiano. Por eso, exponemos una pequeña parte del testimonio de un familiar reparado y víctima real: "A mi papá lo mataron, le metieron piedras en el cuerpo y lo tiraron al río. Nunca encontraron su cadáver... [El Colectivo me informó] que al final ellos se quedarían con un porcentaje del dinero que recibiéramos" (Palomino, 2011), del proceso adelantado en el marco del SIDH.

Por esto, rechazamos la deslegitimación del $\mathrm{SIDH}$, pues no debe impactar más que "hasta las masacres en Colombia se las roben o se hable de desfalco y no de reparación", ${ }^{13}$ que el hecho de que el Estado coadyuve a asesinar con sevicia mediante grupos paramilitares y omisiones y ayudas de sus agentes oficiales, a personas inocentes y en condiciones de marginalidad, pues efectivamente sin la esfera internacional la cruel realidad de Mapiripán habría quedado impune.

\section{Al parecer}

un caso de errores compartidos. Del Estado y su aparato militar y de justicia. De unos particulares que quisieron hacer negocio con un hecho lamentable... Del... [SIDH], por su propia naturaleza y estructura. El SIDH es falible... La justicia humana es falible, sea nacional o transnacional, la Corte IDH funciona como justicia subsidiaria. Por esta razón, a ella no le corresponde investigar los crímenes nacionales, pues esta es una labor de los aparatos investigativos internos. ${ }^{14}$

Como estrategia preventiva para evitar hechos como la reparación a falsas victimas el gobierno creó la Agencia Nacional de Defensa Jurídica del Estado, aunque debería bastar con la óptima actuación de los entes ya creados.

13 Foro Universidad Sergio Arboleda. Carrusel de las víctimas! www. uscateguiesinocente.com. Consultado el 17.7.2012.

14 http://www.ambitojuridico.com/BancoConocimiento/N/noti11112105. Consultado el 21 de octubre de 2014. 


\section{Soberanía y armonización de ordenamientos jurídicos por control de convencionalidad. Beneficios de la política internacional de la posguerra}

El control de convencionalidad propicia la aplicación de normas locales acordes con el cuerpo iuris internacional. Existe un control de convencionalidad difuso y uno concentrado. El difuso lo realizan los órganos del poder judicial del Estado, de acuerdo con el derecho constitucional y el Derecho Internacional de los Derechos Humanos (DIDDHH). El concentrado lo ejerce la Corte IDH aplicando la CADH en procedimientos contenciosos. En Colombia y en sendos ordenamientos jurídicos, los jueces "forzados por las circunstancias, han incluido como variable real de sus decisiones a la CADH y a los estándares y reglas articulados por las sentencias de la Corte IDH" (Quinche, 2009, pp. 163-190).

Así, en diversos fallos de jurisdicción ordinaria "como la primera sentencia proferida por la jurisdicción de Justicia y Paz... contra del paramilitar Wilson Salazar Carrascal, alias el loro, ${ }^{15}$... el sistema de reparaciones acoge las reglas de la Corte IDH". ${ }^{16,17}$ Entonces, mientras que

los tribunales constitucionales controlan la constitucionalidad, el tribunal internacional de DD. HH. resuelve acerca de la convencionalidad

15 Ver Tribunal Superior de Bogotá. Sala de Justicia y Paz. Sentencia de marzo 19 de 2009. Rad.11001600253200680526.

16 Ver Juzgado 56 Penal del Circuito-Bogotá. Sentencia-condenatoria de enero.29 de 2009; Rad. 110013104056-2008-00016-00/200800016.

17 Ver Consejo de Estado. Sala de lo Contencioso Administrativo. Sección 3ra. Sentencia de enero 28 de 2009. Rad. 20030015801. de esos actos. A través del control de constitucionalidad los órganos internos procuran conformar la actividad del poder público $-\mathrm{y}$, eventualmente, de otros agentes sociales-al orden que entraña el Estado de Derecho en una sociedad democrática. El tribunal interamericano... pretende conformar esa actividad al orden internacional acogido en la convención fundadora de la jurisdicción interamericana y aceptado por los Estados partes en ejercicio de su soberanía (caso Tibi vs. Ecuador, 2004).

El control de convencionalidad entonces, "no se ocupa en sí de las cuestiones locales sino que su tarea es la de inspeccionar si los países han violado o no las convenciones sujetas a su competencia" (Albar y Cancado, 1998, p. 584), ni de modificar el derecho local "por ende no se convierte en una cuarta instancia que deja sin efecto las leyes de los países" (Hitters, 2008, p. 1169), pretendiendo evitar que el Estado “incurra en responsabilidad estatal (arts. 1.1 y 2)" (Hitters, 2008, p. 875). De este modo, su naturaleza jurídica se estructura en una, "especie de casación regional que sirve para unificar la interpretación jurídica de los países plegados al modelo, que abarca en el ámbito interamericano más de trescientos millones de habitantes". ${ }^{18} \mathrm{El}$ control de convencionalidad refuerza el derecho a la verdad y garantiza que las reclamaciones de reparación no configuren cargas procesales excesivas que revictimicen a los lesionados y sus causahabientes. Posibilita además, en el caso de que aparezcan "nuevos hechos o pruebas que puedan permitir la determinación de

18 Ver Tratado UE, art. 56: casación ante el Tribunal de Luxemburgo, contra sentencias del órgano jurisdiccional de Primera Instancia. 
los responsables... [que] puedan ser reabiertas las investigaciones, incluso si existe una sentencia absolutoria en calidad de cosa juzgada". ${ }^{19}$

En consecuencia, la violación de obligaciones internacionales o supranacionales conlleva la adecuación de los ordenamientos jurídicos internos sin que esto genere riesgo alguno a la soberanía, sino por el contrario, cristaliza su armonización interméstica y configura un verdadero Estado soberano, en el supuesto que los sujetos de derecho internacional contemporáneo actúen conforme al deber ser. La consolidación plena del cc podría generar una congestión judicial interamericana mayor a la que ya presentan los ordenamientos jurídicos internos, lo que probaría las violaciones sistemáticas estatales que configuran una especie de terrorismo soberano. Así, una verdadera soberanía debe estar armonizada con las normatividades internacionales que acoge voluntariamente y aquellas que tácitamente lo obligan como el Ius Cogens. El viejo problema visible de ser los Estados jueces y partes en un mismo asunto, lo que se cristaliza en la dominación del hegemón en los organismos internacionales. La efectividad de los ordenamientos jurídicos internos debe reflejarse en la inactividad de los instrumentos internacionales de protección de derechos.

\section{CONCLUSIONES}

1. El diagnóstico de seguridad internacional contemporáneo debe resultar del diagnósti-

19 Ver caso Masacre de La Rochela vs. Colombia. Sentencia del 11 de mayo de 2007. Serie C n. ${ }^{\circ}$ 163, párr. 197. co multilateral y multidimensional. De preferencia, con enfoques regionales y culturales, para perseguir un objetivo: el mantenimiento de la paz y seguridad internacionales de todos los Estados, no solo de los intereses centrales. Colombia deberá insertarse decididamente dentro del proceso de integración latinoamericano, en especial, para mitigar las asimetrías del sistema mundo.

2. La dependencia política internacional de la política norteamericana se convierte en una amenaza de intervención armada para cualquiera que no piense lo mismo. Sin embargo, cualquier diagnóstico en RR. II. posterior a 2008 debe partir de una concepción de multipolaridad.

3. La política exterior amigo-enemigo es insostenible en el sistema mundo de 2013. "En política no hay verdades absolutas ni situaciones estáticas. Lo que funcionó ayer puede no funcionar hoy, y los dogmas de ayer puede que no tengan significado mañana" (Gordon, 2006). El condicionamiento norteamericano a través del diagnóstico del conflicto incrementó la violencia doméstica colombiana, al militarizar la lucha interna como única respuesta a la narcoviolencia, en sus diversas modalidades.

4. La dominación territorial de actores no estatales, con el visto bueno de las autoridades nacionales, y el concurso de las FF. AA. desborda la clasificación de Estados fallidos y da paso a la concepción propia denominada Estados superados por actores ilegales para- 
estatales o no estatales, como son los paramilitares o las disfrazadas Bacrim.

5. Lo anterior genera el statu quo de los círculos viciosos, configurando la sistematización del uso de la violencia, que usada en diferentes escalas permitirá que los mismos grupos asciendan en el sistema político o desciendan para evitar los riesgos de penalización. Es decir, cuando nuevamente las Bacrim enciendan su maquinaria de guerra, seguramente el Estado les abrirá un espacio político, y posteriormente las reinsertará, volviendo a considerar sus remanentes como grupos de crimen organizado. Un grupo terrorista que se proclama antiterrorista y se convierte en actor político evidencia la ambigüedad conceptual reflejada en definiciones meramente políticas, por ende coyunturales.

6. La globalización representa el escenario multilateral adecuado para estudiar los conflictos modernos. "El conflicto es un choque de voluntades y no siempre se resuelve a través del empleo de la violencia.... la incertidumbre política nutre la incertidumbre estratégica, características del orden internacional globalizado" (Tello, 2004, p.s.d.). Así esta sea legítima o legitimada (Tello, 2004, p.s.d.), EE. uu. hace presencia en América Central y el Caribe y cuenta con inmunidad militar en bases militares colombianas.

7. En Colombia y en el sistema mundo se es claramente actor político mediante el uso sistemático de la violencia. "El terrorismo sirve para llegar a la mesa de negociaciones" (Ze- raoui, 2011, p. 258). Como por ejemplo, se negocia con las Farc en la entrada de vientos electorales presidenciales. Otros considerados terroristas se enfilan para gobernar el Estado colombiano.

8. Los lugares donde se ejecutan grandes megaproyectos comerciales extranjeros es justamente donde existen más grupos de extrema derecha que son los que colaboran con el trabajo sucio que no pueden reportar las sociedades militares privadas (SMP), reemplazando la estructura privada -o híbridaen cuanto a su legalidad se refiere, a las estructuras insuficientes de seguridad pública del Estado.

9. Existió la masacre de Mapiripán y el Estado reconoció su responsabilidad por el apoyo militar directo en el descuartizamiento de personas. Es el Estado quien debe determinar las víctimas, y actualmente, sigue omitiendo su deber. Si existen falsas víctimas, este hecho no anula la cruel realidad y la responsabilidad del Estado. Aquellos que no fueron identificados como víctimas deben ser la prioridad, los maleantes deben pasar a un plano secundario. La masacre no puede centrarse en un aspecto cuantitativo. El negacionismo afecta el derecho a la verdad. Así se contribuirá efectivamente al mantenimiento de la paz y la seguridad internacionales bajo el concierto de las Naciones Unidas.

10.Las sentencias internacionales contribuyen a un Estado colombiano con menor impunidad. Pero muchas veces el no asumir cier- 
tas posiciones internacionales conlleva consecuencias políticas que generalmente son más lesivas que las sanciones jurídicas.

11. El mundo de la posguerra presencia un escenario multilateral de constante violación de normas imperativas -ius cogens- que en la práctica internacional siguen siendo "relaciones de negociación" (Álvarez, 1999, p. 87). Un sistema "de principios democráticos, o mejor, occidentalizados, sin eco en la realidad social" (Fals Borda et al. 2001). Demostrado por "injusticias, desigualdades y exclusiones y que tienden a ser propositivas en contextos históricos específicos" (Archila, 2001, p. 18).

Los diagnósticos soberanos y no superados podrían evitar que la cooperación se transforme en intervención o en dominación (Arias, 2014, p. 77).

\section{Referencias}

Albar, G. y Cancado Trinidade, A. (1998). Reflexiones sobre el futuro del sistema interamericano de derechos humanos. En J. Méndez y F. Cox (Eds.), El futuro del sistema interamericano de protección de los derechos humanos. San José: Instituto Interamericano de Derechos Humanos.

Álvarez Zárate, J. M. (1999). Cambio de jurisprudencia de la Corte Constitucional en materia internacional. En Homo luris. Ensayos de Derecho Contemporáneo. Bogotá: Universidad Externado de Colombia.
Amicus Curiae. (s.f.). Obtenido de Cejil: http:// cejil.org/amicus-curiae

Archila, M. (2001). Vida, pasión y... de los movimientos sociales en Colombia. En M. Archila y M. Pardo (Eds.), Movimientos sociales, Estado y democracia en Colombia. Bogotá: CES/Universidad Nacional/ICANH.

Arenal, C. del. (2010). Introducción a las relaciones internacionales. (Cuarta Ed.). Madrid, España: Ed. Tecnos.

Arias Henao, D. P. (2014). Investigación comparativa transcontextual en relaciones internacionales narcoviolentas. Revista de Relaciones Internacionales, Estrategia y Seguridad, 9(2), 77-99.

Arias Henao, D. P. y Cieza, D. (2010). Violencia y políticas de derechos humanos: reflexiones a partir del caso argentino. Conferencia en el II Congreso Internacional de Derecho Constitucional de la Universidad Libre de Colombia, 13-15 de octubre. Bogotá.

Arroyo, G. (1996). Resumen de la obra de Samuel Huntington The Clash of Civilizations and the remaking of world order. New York: Simon \& Schuster. 1996.

Azzelini, D. y Kanzleiter, B. (2005). La privatización de las guerra\$: paramilitares, "señores de la guerra" y ejércitos privados como actores del nuevo orden bélico. Cochabamba: Centro de Documentación e Información Bolivia. 
Buzan, B. y Waever, O. (2003). Regions and Powers. The Structure of International Security. Cambridge: Cambridge University Press.

Calvo Ospina, H. (2005). Colombia como en Irak: guerra privada en Colombia. Le Monde Diplomatique.

Caso Suárez Rosero vs. Ecuador. (Corte IDH). Serie C, n. ${ }^{\circ}$ 35, párrafo. 98. (Noviembre 12 de 1997).

Caso Castillo Petruzzi y otros vs. Perú. (Corte IDH). Sentencia de 30.5.1999. Serie C, n. ${ }^{\circ} 52$. (Mayo 30 de 1999).

Caso Myrna Mack Chang vs. Guatemala. (Corte IDH). Sentencia de 25.11.2003, Serie C n. ${ }^{\circ}$ 101. Voto razonado del juez Sergio García. (Noviembre 25 de 2003).

Caso Tibi vs. Ecuador. Voto concurrente razonado del juez Sergio García Ramírez, párrafo 3. (Septiembre 7 de 2004).

Caso de la Masacre de Mapiripán vs. Colombia. Excepciones preliminares y reconocimiento de responsabilidad. Serie $\mathrm{C} n{ }^{\circ}{ }^{122}$. (Marzo 7 de 2005).

Caso Masacre La Rochela vs. Colombia. (Corte IDH). Sentencia 11.5.2007. Serie C n. ${ }^{\circ} 163$. (Mayo 11 de 2007).

Ccajar: Comunicado a la opinión pública. (1 de noviembre de 2011). Obtenido de Colectivo de Abogados José Alvear Restrepo: www.co-
lectivodeabogados.org/CCAJAR-Comunicadoa-la-opinion

Consejo de Estado. Sala de lo Contencioso Administrativo. Sección Tercera. Sentencia 30340 (R-20030015801). (M. P.: Enrique Gil Botero; enero 28 de 2009).

Corte Interamericana de Derechos Humanos. Sentencia de 25 de noviembre de 2003.

Corte Interamericana de Derechos Humanos. Resolución 23 de la sentencia del 15 de septiembre de 2005.

Cubides, F. (2005). Burocracias armadas: el problema de la organización en el entramado de las violencias colombianas. Bogotá: Grupo Editorial Norma.

Decisión histórica: la CIDH admite petición del General Uscátegui. (13 de noviembre de 2014). Obtenido de uscateguiesinocente: www.uscateguiesinocente.com

Duncan, G. (2005). Narcotraficantes, mafiosos y guerreros. Historia de una subordinación. En A. Rangel y G. Duncan, Narcotráfico en Colombia: economía y violencia. Bogotá: Fundación Seguridad y Democracia.

Echandía Castilla, C., Bechara, E. y Cabrera, I. (2010). Colombia: estado del conflicto armado al final de la administración de Álvaro Uribe. En H. Mathieu y C. Niño (Eds.), Seguridad regional en América Latina y el Caribe (págs. 136-172). Anuario 2010. Bogotá: Friedrich Ebert Stiftung. 
El coloquio de los perros. (s.f.). Obtenido de elcoloquiodelosperros: www.elcoloquiodelosperros.com/coloqterror/terrorintrod.htm.

Fals Borda et al. (2001). Movimientos sociales, Estado y democracia en Colombia. Bogotá: Universidad Nacional de Colombia. Centro de Estudios Sociales. Instituto Colombiano de Antropología e Historia.

Fernández, P. (6 de septiembre de 2014). Niall Ferguson: "La desigualdad no es una barrera para el desarrollo económico". Obtenido de The Clinic: www.theclinic.cl/2014/09/06/ niall-ferguson-la-desigualdad-no-es-una-barrera-para-el-desarrollo-economico/.

Fiscalía denuncia falsos muertos en masacre de Mapiripán. (25 de octubre de 2011). Obtenido de El Tiempo: http://www.eltiempo.com/ archivo/documento/CMS-10636224

Gallón Giraldo, G. (s.f.). Política de defensa y seguridad democrática, capítulo VII sobre el Plan de Seguridad Democrática, punto 5 sobre la Promoción de la cooperación ciudadana. Manuscrito presentado para su publicación.

Ganaderos financiaron la masacre de Mapiripán: Exparamilitar. (18 de enero de 2012). Obtenido de El Espectador: http://www.elespectador.com/noticias/judicial/ganaderosfinanciaron-masacre-de-mapiripan-exparamilita-articulo-321684

Gordon, P. (Julio-Agosto de 2006). The End of the Bush Revolution. Obtenido de Foreign Affairs: http://www.foreignaffairs.com/arti- cles/61734/philip-h-gordon/the-end-of-thebush-revolution

García, J. F. y Verdugo, S. (Diciembre de 2011). Radiografía política al Sistema Interamericano de DD. HH. Santiago: Libertad y Desarrollo.

García Ramírez, S. (Julio-Diciembre de 2011). El control judicial interno de constitucionalidad. IUS, 5(28), 123-159.

González, F., Bolívar, I. y Vásquez, T. (2003). Violencia política en Colombia. De la nación fragmentada a la construcción del Estado. Bogotá: Centro de Investigación y Educación Popular.

Howland, T. (6 de febrero de 2012). 'Conflicto colombiano ya duró demasiado'. Recuperado el 21 de octubre de 2012, de El Tiempo: http://www.eltiempo.com/archivo/documento/MAM-5172085

Hitters, J. (2007). Responsabilidad del Estado por violación de Tratados Internacionales. EI que "rompe" (aunque sea el Estado) paga. Obtenido de Redalic.org: http://www.redalyc. org/articulo.oa?id=82050108

Hitters, J. (2008) ¿Son vinculantes los pronunciamientos de la Comisión y de la Corte Interamericana de Derechos Humanos? Revista Iberoamericana de Derecho Procesal Constitucional, (10), 131-156.

Hitters, J. (2009). Control de constitucionalidad y control de convencionalidad. Comparación. Estudios constitucionales, 7(2), 109-128. 
Huguet Polo, A. (Diciembre de 1991). Las tesis de Fukuyama sobre el fin de la historia. Obtenido de Trpod: http://huguet.tripod.com/fukuyama.htm

Human Rigths Watch. (2012). Informe Mundial 2012: Capítulos de la Región de las Américas.

Juzgado 56 Penal del Circuito de Bogotá. Sentencia condenatoria n. ${ }^{\circ} 110013104056-$ 2008-00016-00 NI 2008-00016. (Enero 29 de 2009).

Del Arenal, C. (2007). Introducción a las relaciones internacionales. Madrid: Tecnos.

Kissinger, H. (1996). Diplomacia. Barcelona: Ediciones B, S. A.

López Restrepo, A. (2005). Conflicto interno y narcotráfico entre 1970 y 2005. En A. Rangel y G. Duncan, Narcotráfico en Colombia. Economía y Violencia. Bogotá: Fundación Seguridad y Democracia.

'Los abogados negociaron con la masacre de Mapiripán'. (27 de octubre de 2011). Obtenido de El Espectador: http://www.elespectador. com/noticias/judicial/los-abogados-negociaron-masacre-de-mapiripan-articulo-308036

Mapiripán: dudas y certezas de una masacre. (12 de febrero de 2012). Obtenido de Semana: www.semana.com/nacion/mapiripan-dudas-certezas-masacre/174190-3.aspx

Münkler, H. (2005). Viejas y nuevas guerras: asimetría y privatización de la violencia. Madrid: Siglo XXI de España Editores, S.A.
Münkler, H. (2002). Entrevista con Eberhard Sens. Berlin: Lettre International.

Nye, J. (4 de abril de 2006). Mijail Gorbachov y el fin de la guerra fría. Obtenido de El País: http://elpais.com/diario/2006/04/04/opinion/1144101614_850215.html

Niño Guarnizo, C. (2011). La seguridad de América Latina: respuestas fragmentadas a desafíos transnacionales. En H. Mathieu y C. Niño, Anuario 2011, de la seguridad regional en América Latina y el Caribe. Bogotá: Friedrich Ebert Stiftung.

Nomberto, V. R. (Febrero 23 de 2010). El choque de civilizaciones según Samuel Phillips Huntington. Obtenido de Víctor R. Nomberto, Doctor en Ciencias Sociales: http://blog.pucp. edu.pe/item/89125/el-choque-de-civilizaciones-segun-samuel-phillips-huntington

Nye, J. (marzo 28 de 2006). Mijail Gorbachov y el fin de la guerra fría. Obtenido de Proyect Syndicate: http://www.project-syndicate.org/ commentary/mikhail-gorbachev-and-the-endof-the-cold-war/spanish

Organización de los Estados Americanos (s.f.). Comisión Interamericana de Derechos Humanos. Documentos básicos. Obtenido de Organización de los Estados Americanos: www. oas.org/es/cidh/mandato/Basicos/intro.asp.

Palacios, M. (2006). De populistas, mandarines y violencias. Luchas por el poder. Bogotá: Editorial Planeta. 
Palomino, S. (23 de noviembre de 2011). Mapiripán: ¿Y ahora las víctimas les debemos al Estado y a los culpables de la masacre? Obtenido de Semana: www.semana.com/nacion/ mapiripan-ahora-victimas-debemos-estadoculpables-masacre/167978-3.aspx

Pizarro Leongómez, E. (2004). Una democracia asediada: balance y perspectivas del conflicto armado en Colombia. Bogotá: Grupo Editorial Norma.

Polaridad, Unipolaridad, Bipolaridad, La multipolaridad, No polaridad, La medición de la concentración de poder. (s.f.). Obtenido de ECENTRO: http://centrodeartigos.com/articulos-enciclopedicos/article_87775.html.

Quinche Ramírez, M. F. (2009). El control de convencionalidad y el sistema colombiano. Revista Iberoamericana de Derecho Procesal Constitucional, (12), 163-190.

Redacción Justicia. (25 de octubre de 2011). Fiscalía denuncia falsos muertos en masacre de Mapiripán. Obtenido de El Tiempo: http:// www.eltiempo.com/archivo/documento/ CMS-10636224

Rey Cantor, E., García Ramírez, S., Gonzaíni, O. (2008). Control de convencionalidad de leyes y derechos humanos: homenaje a Héctor FixZamudio. México: Porrúa.

Rossi, A. (2009). Radiografía del narcotráfico. Le Monde Diplomatique, (118).
Salazar, A. M. (2002). Seguridad nacional hoy: el reto de las democracias. México: Editorial Aguilar.

Sassen, S. (25 de enero de 2000). Un nuevo campo transfronterizo para actores públicos y privados. Obtenido de Nueva geografía política: http://sindominio.net/arkitzean/multitudes/multitudes3/nueva_geografia_politica. htm.

Silva Michelena, J. (1987). Política y bloques de poder: crisis en el sistema mundial (Séptima ed.). Madrid: Siglo XXI Editores.

Tello, Á. (2004). La globalización y la seguridad internacional. Conferencia presentada en el Círculo de Legisladores de la Nación Argentina.

Tokatlian, J. (s.f.). Posguerra fría y política exterior. De la autonomía relativa a la autonomíaambigua. Obtenido de banrepcultural: www. banrepcultural.org/sites/default/files/lablaa/ revistas/analisispolitico/ap28.pdf

TribunalSuperior de Bogotá.Sala de Justiciay Paz. Sentencia Rad. 11001600253200680526. (Marzo 19 de 2009).

Zeraoui, Z. (2008). Seguridad internacional y terrorismo. En Las relaciones internacionales de América Latina. Argentina - Chile - México. Transitando los inicios del siglo XXI. Santiago de Chile: Ril Editores.

Zeraoui, Z. (2011). Los procesos mundiales contemporáneos: un mundo transformado. México: Editorial Trillas. 